\title{
Neighbourhood renewal in Victoria, Australia: An effective way to address social inclusion
}

\author{
Ms Margaret Shield \\ Dr Melissa Graham \\ Professor Ann Taket
}

Affiliation:

Centre for Health through Action on Social Exclusion (CHASE), School of Health and Social Development, Deakin University.

\begin{abstract}
People who live in disadvantaged communities are at increased risk of social exclusion through diminished access and quality of services, lack of opportunity and feeling powerless over decisions relating to their neighbourhoods. Neighbourhood Renewal (NR) is a Victorian State Government initiative that seeks to address this. This paper presents the findings from two individual project sites, side-by-side. Data were collected in 2004/5 and 2009 using face-toface interviewing with convenience samples of $900 \mathrm{NR}$ residents across the two NR sites at each time period. A comparison group for each NR site consisted of a sample of 150 people living in the same suburb or town but outside the NR site, data were collected by telephone. Data were analysed separately for each NR project site. Findings indicate that neighbourhood renewal strategies can be effective in improving trust in government, perceptions of community participation, influence and control over community decisions and improved services. Community level strategies are valuable in addressing area-level determinants to improve social inclusion. The successes of the NR scheme support the implementation and continuation of area-specific interventions to address disadvantage and social exclusion across Victoria, Australia.
\end{abstract}

Keywords: Neighbourhood renewal, Social inclusion, Social exclusion, Disadvantage, Neighbourhood intervention, Community 
Neighbourhood renewal: an effective way to address social inclusion

\section{Introduction}

It is evidenced that area-level disadvantage is associated with increased mortality and morbidity across a range of health conditions and diseases (Adams, et al., 2009; Deans, et al., 2009; Feldman, Warr, Tacticos, \& Kelaher, 2009; Major, et al., 2010). There are demonstrated links between area-level disadvantage and social exclusion (Baum \& Gleeson, 2010; Hemphill, et al., 2010; Stewart, et al., 2008; Tanton, Harding, Daly, McNamara, \& Yap, 2010) however social exclusion is also considered to be an indicator of disadvantage (Scutella \& Wilkins, 2010; Tanton, et al., 2010). Regardless of how social exclusion is conceptualised, measured and investigated, the association between social exclusion and poor health is well documented (Popay, et al., 2008).

Different conceptualisations of social exclusion abound in the academic literature; what they all have in common is that social exclusion is conceived of as multidimensional, and where definitions differ in is the number and type of dimensions drawn upon (Taket, et al., 2009). One particularly useful definition of exclusion is that offered by Popay et al. (2008) in their work for the WHO Commission on Social Determinants of Health:

Exclusion consists of dynamic, multi-dimensional processes driven by unequal power relationships interacting across four main dimensions economic, political, social and cultural - and at different levels including individual, household, group, community, country and global levels. It results in a continuum of inclusion/exclusion characterised by unequal access to resources, capabilities and rights which leads to health inequalities.' (p. 2)

Social exclusion is defined, in operational terms, by the Australian Government as being persons or areas who experience multiple disadvantage (Australian Social Inclusion Board, 2010), more specifically, social exclusion can be conceptualised as a lack of, or reduced access to: suitable housing, employment, education, transport, and health services which results in lower levels of participation in various aspects of life (Popay, et al., 2008). In an attempt to address the multiple disadvantage associated with social exclusion, the Australian Government has made social inclusion a priority area (Australian Government, 2009). Thus, several policies, programs and interventions at both local and national levels, have been developed and implemented in order to address this priority (Social Inclusion Unit, 2011).

In 2001, the Victorian State Government implemented the NR scheme in an effort to reduce the area-level disadvantage across Victoria; NR has been implemented in 21 project sites to date (Neighbourhood Renewal, 2010b). The specific projects and interventions vary from site to site as NR adopts an area-specific approach. The six objectives of the NR scheme are:

- increasing community pride and participation;

- enhancing housing and the physical environment;

- lifting employment and learning opportunities and expanding local economies;

- improving personal safety and reducing crime;

- promoting health and wellbeing; and 
Neighbourhood renewal: an effective way to address social inclusion

- improving government responsiveness (Neighbourhood Renewal, 2010a).

Each of these objectives relates broadly to social inclusion. This paper aims to compare and contrast the relative successes of two project sites for the NR scheme in Victoria in increasing some of the aspects associated with social inclusion.

Area-level approaches to address area-level issues such as community disadvantage and community level social exclusion have been adopted elsewhere with varying levels of success (Clark \& Southern, 2006; Monks \& Robertson, 2009; Stafford, Nazroo, Popay, \& Whitehead, 2008; Thomson, Atkinson, Petticrew, \& Kearns, 2006). There are several difficulties inherent in measuring the success of such interventions, for example, the discrepancy between follow-up times and the lag between intervention and community perception of improvement (Stafford, et al., 2008). Additionally, as in the case of the Victorian NR initiative, area-specific interventions can result in varying success across different indicators, thus making broad evaluations of the initiative as a whole, difficult and potentially misleading.

This study draws on the evaluations from two NR sites in Victoria, comparing and contrasting their relative success, specifically with regard to the indicators measuring aspects of social inclusion. Full reports of the analysis are available (CHASE).

\section{Methods}

NR is a Victorian State Government scheme that aims to narrow the gap between disadvantaged communities and the rest of the state. Areas are selected to be a part of NR when there is a high level of relative disadvantage in comparison the rest of the state. A range of indicators are used to assess disadvantage including: concentrations of public housing, mean taxable income, crime, employment and education. The research team were engaged by the Neighbourhood Renewal Branch within the Department of Human Services, Victoria to analyse the data from two NR sites only. Therefore, this study draws on data collected by the Neighbourhood Renewal Branch in Corio Norlane and Colac NR project sites.

Area-specific programs were implemented as a part of the NR strategy, to address the disadvantage present in each specific project site. Therefore the interventions for each of the project sites addressed in this paper were not exactly the same. Details about the specific interventions for Corio Norlane can be found at: http://www.corionorlane.org.au/index.php and details of the specific interventions implemented in Colac can be found at: http://www.communityhubinc.org.au/.

\section{Study design}

A quasi-experimental community trial was used to evaluate the success of NR. Standardised questionnaires were administered at each wave of data collection, to residents within the NR project sites and to comparison groups consisting of residents living in the same suburb or town but outside the NR sites. Surveys were conducted in three waves, the first wave of data collection was conducted within the first four years of the initiation of NR and subsequent waves have been conducted at two year intervals, with the third wave of data collection occurring in 2009. For each wave of data collection, data were collected from both the NR group and the comparison group. 
Neighbourhood renewal: an effective way to address social inclusion

\section{Sample}

A convenience sampling method was used to recruit participants from the NR sites for each wave of data collection. For Corio Norlane there were a total of 600 participants at each wave of data collection, for Colac there were 300 participants at the first wave and 301 at the third wave. Comparison group participants were recruited using a sample of telephone numbers from the electronic White Pages. In the first wave of data collection there were 149 comparison participants for each site, for the third wave there were 150 participants for each site. Comparison group participants were stratified into deciles according to the Australian Bureau of Statistics Index for Relative Socioeconomic Disadvantage (Australian Bureau of Statistics, 2008).

\section{Data Collection}

The standardised questionnaire used for data collection is part of a standard framework for the evaluation of NR and was designed by Salvaris and the Swinburne Institute for Social Research, Melbourne (Salvaris \& Swinburne Institute for Social Research, 2008). Most of the items contained in the questionnaire were answered using a multiple choice format, including three to five item likert scales, yes/no, and choose the response that most applies.

Participants from the NR group were interviewed in-person, by trained local residents of the NR project site. For the comparison group, Computer Assisted Telephone Interviews (CATI) were conducted using a truncated version of the questionnaire. Questions that were only relevant to NR residents were not included in the CATI.

This study used data from the first and third waves of data collection to investigate and compare changes in the responses given for both the NR group and comparison group for each project site, separately.

\section{Variables}

This paper draws on selected indicators that measure aspects of social inclusion. Specifically, this paper analysed responses to survey questions that assess the quality and accessibility of services, government performance, opportunity for education and employment, community participation, sense of belonging, trust, hope, influence and control over the future.

\section{Analysis}

Data were analysed separately for each NR project site. Descriptive statistics were conducted for both the NR and comparison group for each of the items. Chi-square values were calculated in order to test for statistically significant changes between the first (2004/5) and third (2009) wave of data collection. Separate chi-square values were calculated for the NR and comparison group and for each project site so that success within a project area could be assessed and results could be compared between each project area. Separate chi-square values were also calculated for public and private housing residents within the NR project site to assess any differences between these population groups. Statistical significance is reported at 0.01 . 


\section{Perceptions of change}

\section{Results}

NR residents were asked about their perceptions of changes in relation to government performance, opportunity for education, health and welfare services and community participation over the past six to 12 months. There was a statistically significant increase in the percentage of Corio Norlane public housing respondents who perceived an improvement in government performance $(p=0.004)$ and community participation $(p=0.009)$. In contrast, in Colac, statistically significant changes in a direction for the worse were found for private housing residents for both opportunity for education and health and welfare services (Table 1 see after text).

\section{Rating quality and accessibility of services}

A complex pattern of changes in the rating of quality and the accessibility of services were observed over time in both NR sites and comparison sites. For quality and accessibility of services in general there were statistically significant changes for the better in the Colac NR group and no statistically significant change in the Corio Norlane NR or the comparison groups. For opportunities to get satisfactory employment, statistically significant improvement occurred in both NR groups, but not in comparison groups. However there was a statistically significant worsening in quality and availability of services to help find employment in the Colac NR group (Table 2 see after text).

\section{Trust in government and each other}

There were statistically significant improvements in the level of trust for each of the three levels of government in the Corio Norlane NR group; for the Colac NR group, trust significantly improved for federal and state levels only. In contrast, the comparison group's trust decreased significantly for federal and local levels and for state level in Corio Norlane only.

Changes in the level of agreement to statements about trust at the community level were more varied. Levels of trust in people in the area decreased significantly in both NR groups and the Colac comparison group, with no significant change in the Corio Norlane comparison group. There were no statistically significant changes in relation to neighbours. Belief in the strength of the community improved significantly in Corio Norlane but decreased significantly in Colac; in both cases the comparison group showed an increased polarisation of response over time (Table 3 see after text).

\section{Hope, influence and control over the future}

Respondents were asked about their agreement with statements relating to hope, influence and control over the future. When asked about whether or not respondents agreed that they had control over decisions made in their community, there were statistically significant positive trends in both NR groups, while there was increased polarisation in the comparison groups (Table 4 see after text).

\section{Belonging and frequency of participation}

Despite statistically significant changes in survey responses about perceptions of the community and participation, there were limited changes in specific participatory behaviours for either of the project sites or their respective comparison groups. There was a statistically significant decrease in minding a neighbour or friend's child in the Colac NR, however there were concurrent decreases in the percentage of respondents with children under 18 years at home. Interestingly, there were 
statistically significant changes in sense of belonging in both NR groups and the Colac comparison group, and but no statistically significant change in the Corio Norlane comparison group. For the NR groups, the percentage of people neutral about belonging increased, and while in Corio Norlane the percentage lacking a sense of belonging decreased, in Colac it increased (Table 5 see after text).

\section{Discussion}

The Neighbourhood Renewal scheme was initiated in 2001, in 21 project sites across Victoria (Neighbourhood Renewal, 2010b). Overall, this study highlights some encouraging and positive results for both of the NR project sites reported here, with regard to the indicators that measure social inclusion. Despite, and perhaps because of, differences in the approaches and specific interventions within each area (Neighbourhood Renewal, 2010b), there has been varying success in different indicators for each project site. There were also some similarities between project sites in terms of the indicators where NR had a positive impact.

Notably, there was a statistically significant increase in agreement that the Federal and State Governments could be trusted to do what was best for people in their neighbourhoods. This finding suggests that residents of NR areas feel their communities' needs are being considered by the higher levels of government, in terms of broader policies. Despite the broader shifts in both areas towards more trust in the higher levels of government, increases in the percentage of respondents who perceived improvement in government performance over the last six - 12 months was only recorded for Corio Norlane NR respondents not Colac respondents. At face value this may appear counterintuitive however trust was measured across different levels of government whereas performance was not. The association between perceived government performance and trust in government is not necessarily linear (Bouckaert, Laegreid, \& Van de Walle, 2005; Yang \& Holzer, 2006). Additionally, citizen participation may increase trust in government (Halachmi \& Holzer, 2010), but this might not translate into improved government performance.

Similarly, despite a perceived improvement in community participation among Corio Norlane public housing residents, there was limited change in the frequency of individual engagement in specific participatory behaviours for both NR sites and comparison groups. This is suggestive of a disparity between measurements of perceptions and measurements of behaviours. Alternatively, it may be indicative of the difference between perceived changes for the community as a whole, compared with the desire of individual members to be actively involved (Allsop \& Taket, 2003; Forde-Roberts, 1999). Regardless of individual participation in the community, there was a positive shift in feelings of control and influence over decisions that affected the community, amongst people who lived in NR communities.

For Colac, there was a substantial swing $(+20.11, p<0.001)$ in the percentage of respondents who rated the general services in the area as good. Interestingly, this was not apparent when other specific services were addressed, for example opportunities and facilities to get education were less likely to be rated as good, as were opportunities for employment and the services that assist you to find employment. The swing observed for the general question about services could be related to improvements in transport services specifically, as the wording of this question described local services 'like transport, health, education, children, older people etc'. When the Colac NR group were asked specifically about transport, there were substantial improvements to the ratings given.

Journal of Social Inclusion 2 (2) 2011 
Neighbourhood renewal: an effective way to address social inclusion

There are some limitations pertaining to the study design that need to be considered when interpreting the findings. There is likely to be some selection bias in both the comparison and NR group for different reasons. Firstly, the sampling method used for comparison group differed to that used for the NR group. As a convenience sample was used for the NR group there is more scope for selection bias given that participating was on an opt in basis. The use of convenience sampling also meant that a response rate could not be calculated. While the comparison group were recruited using the electronic White Pages, data on the response rate was not collected.

The method of data collection was different for the comparison and NR groups, and extreme responses (e.g. strongly agree or strongly disagree as opposed to agree or disagree) have been shown to be more common in CATI compared to other survey methods (Feveile, Olsen, \& Hogh, 2007). However, the differences in response patterns may have been somewhat mitigated, as five-item likert scales were condensed to three-item scales, thus reducing the tendency for extreme responses. Lastly, there may have been some contamination of the comparison group respondents given their proximity to the project sites. This may have resulted in a dilution of the differences between respondents from the comparison and NR groups for some indicators. Another source of dilution may be that the surveys conducted for the first wave of data collection were done so shortly after the commencement of the NR scheme, instead of beforehand.

A somewhat unique aspect of this study was the use of local residents as interviewers for the face-to-face interviews within the project sites. This was arguably a strength not only for the study design but also the NR scheme, as it upheld the core strategy of increasing participation within communities and is congruent with the principles of socially inclusive research. Additionally, the authors did not have any involvement in the NR scheme aside from the data analysis. Arguably, this was also a strength as the authors did not have any preconceived notions of success or otherwise for the NR scheme.

Regardless of the area-specific interventions implemented, the inherent limitations of the approach utilised and the reporting of the two sites as individual case studies, significant improvements at a community level were found in relation to social inclusion. The relative successes of the NR scheme for each area discussed here provide support for the implementation and continuation of area-specific interventions to address disadvantage and social exclusion across Victoria. The findings bring the inherent value and necessity of area-specific evaluations to the fore. The two NR project sites reported here suggest that significant improvements can be achieved using area-level interventions particularly in regards to improving communities' sense of trust in all levels of government, increases in perceived levels of community participation, influence and control over decision-making, and improved local services and transport. 
Neighbourhood renewal: an effective way to address social inclusion

Table 1: NR respondents' perceptions of change in their local area over the past 6 - 12 months

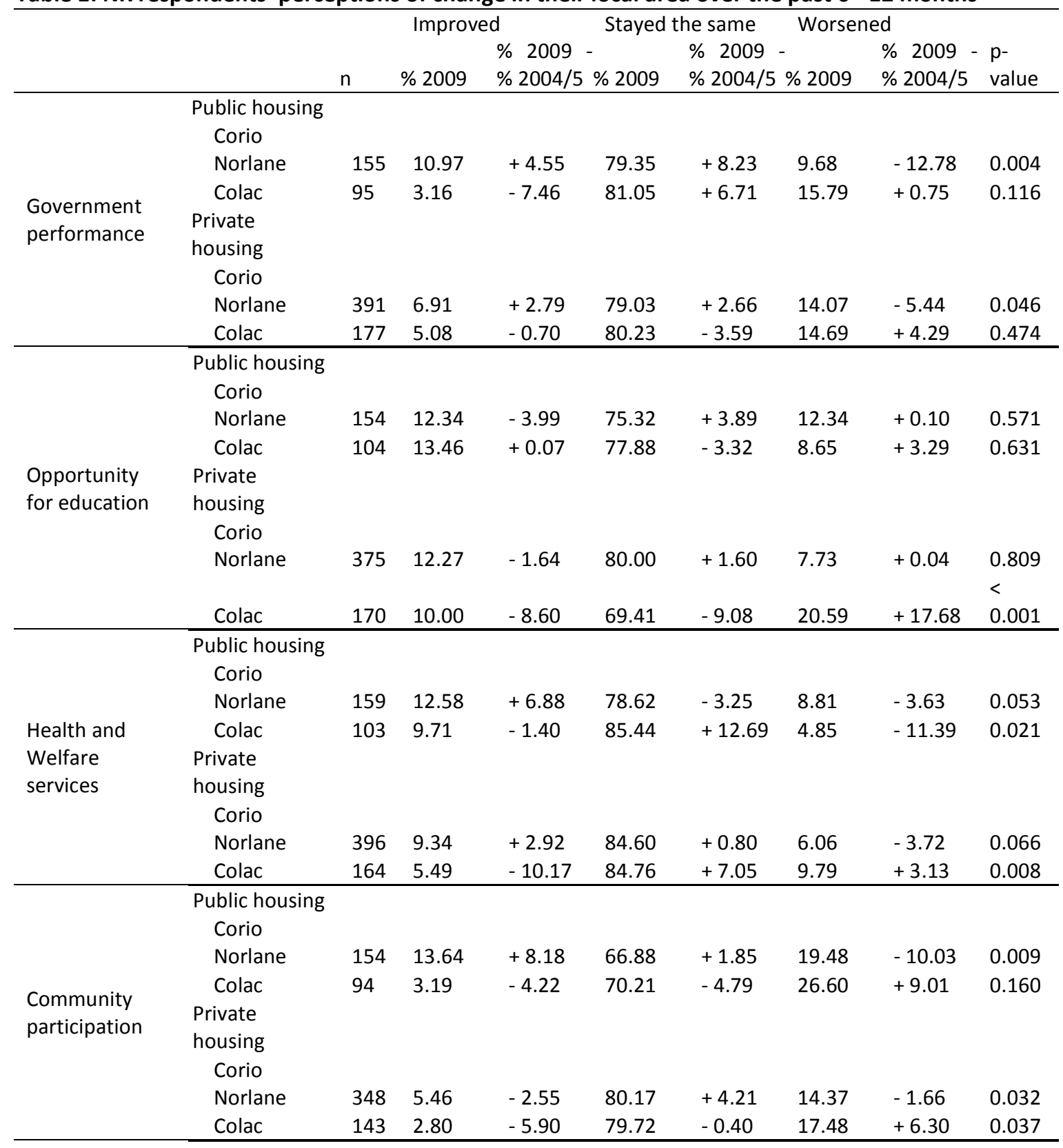

Table 2: Respondents' rating of services and opportunities in their neighbourhood

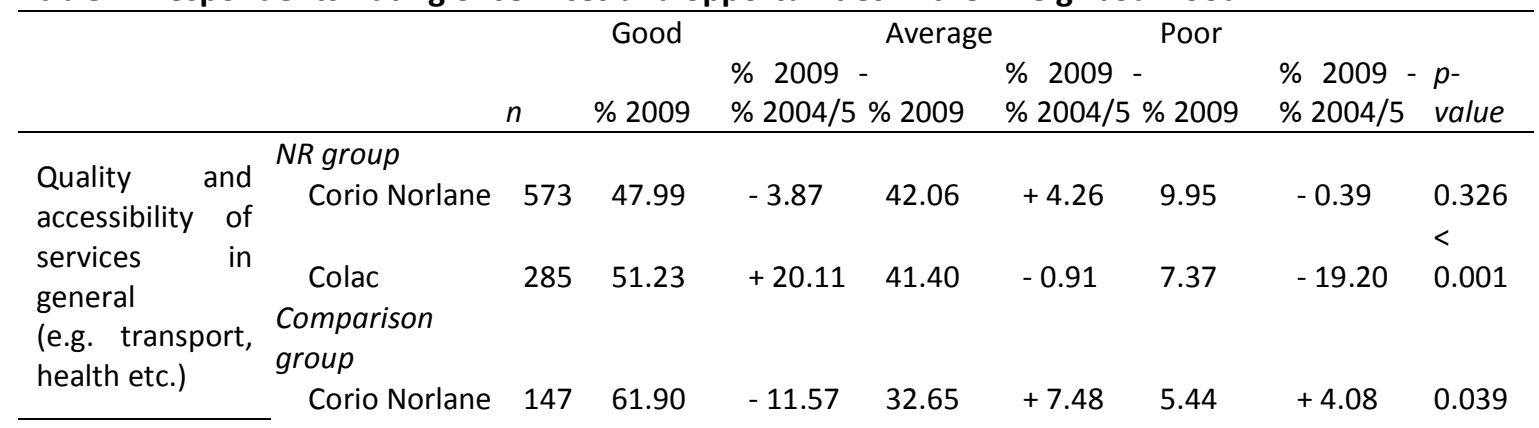

Journal of Social Inclusion 2 (2) 2011 
Neighbourhood renewal: an effective way to address social inclusion

\begin{tabular}{|c|c|c|c|c|c|c|c|c|c|}
\hline & Colac & 150 & 68.67 & +7.98 & 22.00 & -11.79 & 9.33 & +3.81 & 0.054 \\
\hline \multirow{6}{*}{$\begin{array}{l}\text { Opportunities } \\
\text { and facilities to } \\
\text { get education } \\
\text { and training }\end{array}$} & NR group & & & & & & & & \\
\hline & Corio Norlane & 558 & 38.35 & -1.10 & 46.77 & +5.85 & 14.87 & -4.76 & 0.053 \\
\hline & Colac & 290 & 38.62 & -11.21 & 42.41 & +6.77 & 18.97 & +4.44 & 0.023 \\
\hline & $\begin{array}{l}\text { Comparison } \\
\text { group }\end{array}$ & & & & & & & & \\
\hline & Corio Norlane & 146 & 68.49 & -17.43 & 22.60 & +10.63 & 8.90 & +6.79 & 0.001 \\
\hline & Colac & 148 & 56.76 & -10.59 & 30.41 & +3.88 & 12.84 & +6.72 & 0.730 \\
\hline \multirow{6}{*}{$\begin{array}{l}\text { Opportunities } \\
\text { to get } \\
\text { satisfactory } \\
\text { employment }\end{array}$} & NR group & & & & & & & & \\
\hline & Corio Norlane & 559 & 11.27 & -0.94 & 37.03 & +8.48 & 51.70 & -7.55 & 0.010 \\
\hline & $\begin{array}{l}\quad \text { Colac } \\
\text { Comparison } \\
\text { group }\end{array}$ & 285 & 18.25 & -4.85 & 51.93 & +12.62 & 29.82 & -7.77 & 0.010 \\
\hline & Corio Norlane & 144 & 25.00 & -13.46 & 42.36 & +3.13 & 32.64 & +10.33 & 0.034 \\
\hline & Colac & 148 & 39.19 & +5.38 & 45.27 & +1.39 & 15.54 & -6.76 & 0.311 \\
\hline & NR group & & & & & & & & \\
\hline \multirow{4}{*}{$\begin{array}{l}\text { Quality and } \\
\text { availability of } \\
\text { services to help } \\
\text { you find } \\
\text { employment }\end{array}$} & Corio Norlane & 517 & 22.63 & -4.19 & 47.00 & +3.51 & 30.37 & +0.68 & 0.274 \\
\hline & $\begin{array}{l}\text { Colac } \\
\text { Comparison } \\
\text { group }\end{array}$ & 269 & 32.71 & -13.39 & 44.61 & +5.58 & 22.68 & +7.81 & 0.003 \\
\hline & Corio Norlane & 132 & 32.58 & -8.93 & 43.18 & +13.93 & 24.24 & -5.01 & 0.085 \\
\hline & Colac & 142 & 63.38 & +0.39 & 28.87 & +3.67 & 7.75 & -4.06 & 0.477 \\
\hline
\end{tabular}

Table 3: Respondents' level of agreement with statements about trust in government and people in their neighbourhood

\begin{tabular}{|c|c|c|c|c|c|c|c|c|c|}
\hline & & & Agree & & Neithe & & Disagre & & \\
\hline & & $n$ & $\% 2009$ & $\begin{array}{l}\% 2009 \\
\% 2004 / 5\end{array}$ & $\% 2009$ & $\begin{array}{l}\% 2009 \\
\% 2004 / 5\end{array}$ & $\% 2009$ & $\begin{array}{l}\% 2009- \\
\% 2004 / 5\end{array}$ & $\begin{array}{l}p \text { - } \\
\text { value }\end{array}$ \\
\hline \multirow{9}{*}{$\begin{array}{l}\text { Trust in Federal } \\
\text { Government }\end{array}$} & NR group & & & & & & & & \\
\hline & & & & & & & & & $<$ \\
\hline & Corio Norlane & 510 & 29.41 & + 17.77 & 23.14 & +14.93 & 47.45 & -32.70 & 0.001 \\
\hline & & & & & & & & & $<$ \\
\hline & Colac & 255 & 26.67 & +15.20 & 20.39 & +4.98 & 52.94 & -20.18 & 0.001 \\
\hline & $\begin{array}{l}\text { Comparison } \\
\text { group }\end{array}$ & & & & & & & & \\
\hline & & & & & & & & & $<$ \\
\hline & Corio Norlane & 140 & 50.71 & +5.71 & 3.57 & -23.44 & 45.71 & +17.98 & 0.001 \\
\hline & Colac & 147 & 42.86 & +8.57 & 8.84 & -13.30 & 48.30 & +4.73 & 0.007 \\
\hline \multirow{9}{*}{$\begin{array}{l}\text { Trust in State } \\
\text { Government }\end{array}$} & NR group & & & & & & & & \\
\hline & & & & & & & & & $<$ \\
\hline & Corio Norlane & 522 & 31.42 & +12.11 & 23.56 & +12.66 & 45.02 & -24.77 & 0.001 \\
\hline & & & & & & & & & 0.003 \\
\hline & Colac & 257 & 27.63 & +10.63 & 20.23 & +3.63 & 52.14 & -14.26 & \\
\hline & $\begin{array}{l}\text { Comparison } \\
\text { group }\end{array}$ & & & & & & & & \\
\hline & & & & & & & & & $<$ \\
\hline & Corio Norlane & 145 & 51.03 & +14.74 & 6.90 & -18.29 & 42.07 & +3.55 & 0.001 \\
\hline & Colac & 147 & 42.86 & +15.91 & 9.52 & -6.79 & 47.26 & -9.12 & 0.012 \\
\hline \multirow{3}{*}{$\begin{array}{l}\text { Trust in Local } \\
\text { Council }\end{array}$} & NR group & & & & & & & & \\
\hline & Corio Norlane & 541 & 36.60 & +1.30 & 18.11 & +6.73 & 45.29 & -8.03 & 0.003 \\
\hline & Colac & 259 & 28.96 & -0.48 & 19.69 & +9.13 & 51.35 & -8.65 & 0.011 \\
\hline
\end{tabular}

Journal of Social Inclusion 2 (2) 2011 
Neighbourhood renewal: an effective way to address social inclusion

\begin{tabular}{|c|c|c|c|c|c|c|c|c|c|}
\hline & \multicolumn{9}{|l|}{$\begin{array}{l}\text { Comparison } \\
\text { group }\end{array}$} \\
\hline & \multirow[b]{2}{*}{ Corio Norlane } & \multirow[b]{2}{*}{145} & \multirow[b]{2}{*}{48.28} & \multirow[b]{2}{*}{+16.85} & \multirow[b]{2}{*}{4.14} & \multirow[b]{2}{*}{-23.72} & \multirow[b]{2}{*}{47.59} & \multirow[b]{2}{*}{+6.87} & $<$ \\
\hline & & & & & & & & & $\begin{array}{l}0.001 \\
<\end{array}$ \\
\hline & Colac & 146 & 37.67 & -19.27 & 9.59 & -4.30 & 52.74 & +23.57 & 0.001 \\
\hline \multirow{5}{*}{$\begin{array}{l}\text { I can trust most } \\
\text { people in this } \\
\text { area, most of } \\
\text { the time }\end{array}$} & NR group & & & & & & & & \\
\hline & Corio Norlane & 578 & 54.33 & -6.46 & 11.76 & +4.81 & 33.91 & +1.65 & 0.009 \\
\hline & $\begin{array}{l}\quad \text { Colac } \\
\text { Comparison } \\
\text { group }\end{array}$ & 293 & 59.73 & -9.72 & 16.04 & +11.87 & 24.23 & -2.16 & 0.001 \\
\hline & Corio Norlane & 150 & 92.67 & +5.17 & 2.00 & -2.86 & 5.33 & -2.31 & 0.274 \\
\hline & Colac & 150 & 93.33 & -1.84 & 0.00 & -3.54 & 6.67 & +5.29 & 0.006 \\
\hline \multirow{5}{*}{$\begin{array}{l}\text { Neighbours } \\
\text { around here } \\
\text { look out for one } \\
\text { another }\end{array}$} & NR group & & & & & & & & \\
\hline & Corio Norlane & 572 & 66.08 & -3.57 & 9.62 & +2.97 & 24.30 & +0.60 & 0.162 \\
\hline & $\begin{array}{l}\quad \text { Colac } \\
\text { Comparison } \\
\text { group }\end{array}$ & 290 & 64.14 & -10.95 & 12.41 & +5.15 & 23.45 & +5.80 & 0.013 \\
\hline & Corio Norlane & 150 & 88.67 & +4.64 & 2.00 & -7.03 & 9.33 & +2.39 & 0.025 \\
\hline & Colac & 149 & 91.28 & +2.46 & 1.34 & -5.65 & 7.38 & +3.19 & 0.030 \\
\hline \multirow{6}{*}{$\begin{array}{l}\text { This is a strong } \\
\text { community } \\
\text { where people } \\
\text { have a lot in } \\
\text { common }\end{array}$} & NR group & & & & & & & & \\
\hline & Corio Norlane & 542 & 34.32 & +3.92 & 18.08 & +4.95 & 47.60 & -8.87 & 0.008 \\
\hline & $\begin{array}{l}\quad \text { Colac } \\
\text { Comparison } \\
\text { group }\end{array}$ & 273 & 34.80 & -12.39 & 20.15 & +5.91 & 45.05 & +6.48 & 0.010 \\
\hline & & & & & & & & & $<$ \\
\hline & Corio Norlane & 145 & 71.72 & +9.50 & 5.52 & -16.70 & 22.76 & +7.20 & 0.001 \\
\hline & Colac & 148 & 81.08 & +11.36 & 3.38 & - 15.64 & 15.54 & +4.27 & $\begin{array}{l}< \\
0.001\end{array}$ \\
\hline
\end{tabular}

Table 4: Respondents' level of agreement with statements relating to hope, influence and control over the future

\begin{tabular}{|c|c|c|c|c|c|c|c|c|c|}
\hline & & & Agree & & Neither & & Disagre & & \\
\hline & & $n$ & $\% 2009$ & $\begin{array}{l}\% 2009- \\
\% 2004 / 5\end{array}$ & $\% 2009$ & $\begin{array}{ll}\% & 2009 \\
\% & 2004 / 5\end{array}$ & $\% 2009$ & $\begin{array}{l}\% 2009- \\
\% 2004 / 5\end{array}$ & $\begin{array}{l}p \text { - } \\
\text { value }\end{array}$ \\
\hline \multirow{6}{*}{$\begin{array}{l}\text { By working } \\
\text { together people } \\
\text { could improve } \\
\text { this } \\
\text { neighbourhood } \\
\text { and influence } \\
\text { decisions }\end{array}$} & NR group & & & & & & & & \\
\hline & Corio Norlane & 580 & 90.00 & -2.43 & 5.34 & +3.62 & 4.66 & -1.20 & $\begin{array}{l}0.003 \\
<\end{array}$ \\
\hline & Colac & 292 & 78.77 & -12.55 & 15.75 & +9.50 & 5.48 & +3.05 & 0.001 \\
\hline & $\begin{array}{l}\text { Comparison } \\
\text { group }\end{array}$ & & & & & & & & \\
\hline & Corio Norlane & 150 & 89.33 & -2.39 & 0.67 & -4.16 & 10.00 & +6.55 & 0.009 \\
\hline & Colac & 148 & 94.59 & -0.61 & 0.68 & -2.75 & 4.73 & +3.36 & 0.066 \\
\hline \multirow{5}{*}{$\begin{array}{l}\text { By helping } \\
\text { others, you help } \\
\text { yourself in the } \\
\text { long run }\end{array}$} & NR group & & & & & & & & \\
\hline & Corio Norlane & 587 & 94.55 & +0.07 & 3.41 & +0.16 & 2.04 & -0.86 & 0.632 \\
\hline & $\begin{array}{l}\quad \text { Colac } \\
\text { Comparison } \\
\text { group }\end{array}$ & 297 & 82.83 & -5.83 & 13.13 & +6.95 & 4.04 & -1.11 & 0.016 \\
\hline & Corio Norlane & - & - & - & - & - & - & - & - \\
\hline & Colac & - & - & - & - & - & - & - & - \\
\hline
\end{tabular}


Neighbourhood renewal: an effective way to address social inclusion

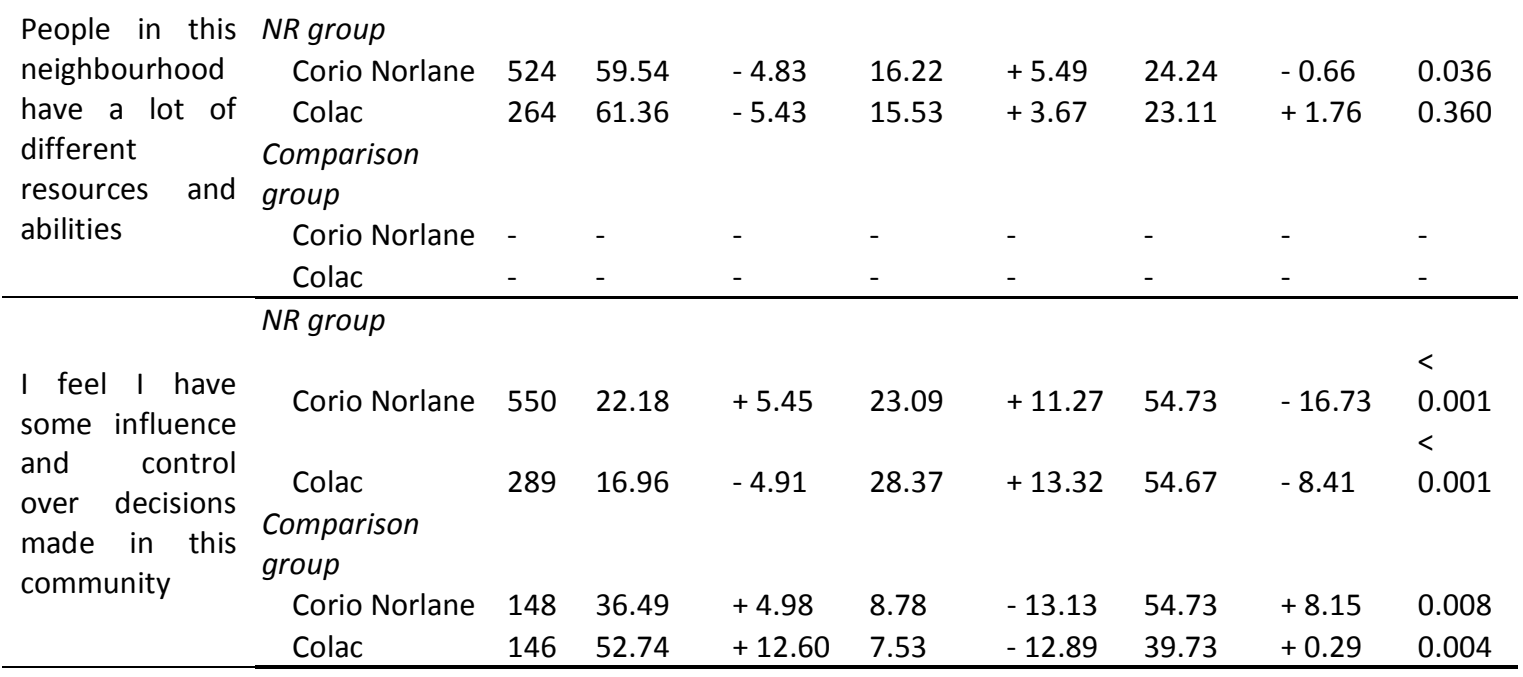

Table 5: Respondents' level of agreement with statements about belonging and frequency of participation

\begin{tabular}{|c|c|c|c|c|c|c|c|c|c|}
\hline & & \multicolumn{2}{|r|}{ Agree } & \multicolumn{3}{|c|}{ Neither } & \multicolumn{2}{|c|}{ Disagree } & \multirow{3}{*}{$\begin{array}{l}p \text { - } \\
\text { value }\end{array}$} \\
\hline & & & & $\% 2009$ & & $\% 2009$ & & \% $2009-$ & \\
\hline & & $n$ & $\% 2009$ & $\% 2004 / 5$ & $\% 2009$ & $\% 2004 / 5$ & $\% 2009$ & $\% 2004 / 5$ & \\
\hline \multirow{7}{*}{$\begin{array}{l}\text { I know quite a } \\
\text { few people in } \\
\text { the neigh'hood }\end{array}$} & NR group & & & & & & & & \\
\hline & Corio Norlane & 586 & 82.94 & +5.76 & 5.80 & +1.20 & 11.26 & -6.97 & 0.003 \\
\hline & Colac & 299 & 78.60 & -4.96 & 8.03 & +4.34 & 13.38 & +0.63 & 0.071 \\
\hline & Comparison & & & & & & & & \\
\hline & group & & & & & & & & \\
\hline & Corio Norlane & 150 & 76.00 & -1.40 & 1.33 & -6.20 & 22.67 & +7.60 & 0.013 \\
\hline & Colac & 150 & 88.00 & +4.44 & 0.00 & -4.79 & 12.00 & +0.36 & 0.025 \\
\hline \multirow{9}{*}{$\begin{array}{l}\text { I feel a sense of } \\
\text { belonging to } \\
\text { this community }\end{array}$} & NR group & & & & & & & & \\
\hline & & & & & & & & & $<$ \\
\hline & Corio Norlane & 571 & 59.72 & -0.21 & 19.09 & +7.86 & 21.19 & -7.65 & 0.001 \\
\hline & & & & & & & & & $<$ \\
\hline & Colac & 288 & 51.04 & -15.04 & 27.08 & +12.05 & 21.88 & +2.99 & 0.001 \\
\hline & Comparison & & & & & & & & \\
\hline & group & & & & & & & & \\
\hline & Corio Norlane & 150 & 82.00 & +3.92 & 4.67 & -5.61 & 13.33 & +1.69 & 0.179 \\
\hline & Colac & 150 & 91.33 & +6.87 & 0.67 & -9.47 & 8.00 & +2.59 & 0.001 \\
\hline \multirow{8}{*}{$\begin{array}{l}\text { Many of my } \\
\text { family and } \\
\text { friends live in } \\
\text { this } \\
\text { neighb'hood }\end{array}$} & NR group & & & & & & & & \\
\hline & & & & & & & & & $<$ \\
\hline & Corio Norlane & 581 & 71.43 & +6.17 & 9.47 & +3.20 & 19.10 & -9.37 & 0.001 \\
\hline & Colac & 300 & 75.33 & +3.67 & 9.33 & +2.67 & 15.33 & -6.33 & 0.088 \\
\hline & Comparison & & & & & & & & \\
\hline & group & & & & & & & & \\
\hline & Corio Norlane & - & - & - & - & - & - & - & - \\
\hline & Colac & - & - & - & - & - & - & - & - \\
\hline \multirow{5}{*}{$\begin{array}{l}\text { I feel generally } \\
\text { valued by the } \\
\text { community }\end{array}$} & NR group & & & & & & & & \\
\hline & Corio Norlane & 531 & 44.63 & +2.47 & 24.86 & +6.58 & 30.51 & -9.04 & 0.003 \\
\hline & Colac & 272 & 37.87 & -8.41 & 31.25 & +9.29 & 30.88 & -0.88 & 0.039 \\
\hline & $\begin{array}{l}\text { Comparison } \\
\text { group }\end{array}$ & & & & & & & & \\
\hline & Corio Norlane & 147 & 68.71 & +10.26 & 10.20 & -16.56 & 21.09 & +6.30 & 0.001 \\
\hline
\end{tabular}


Neighbourhood renewal: an effective way to address social inclusion

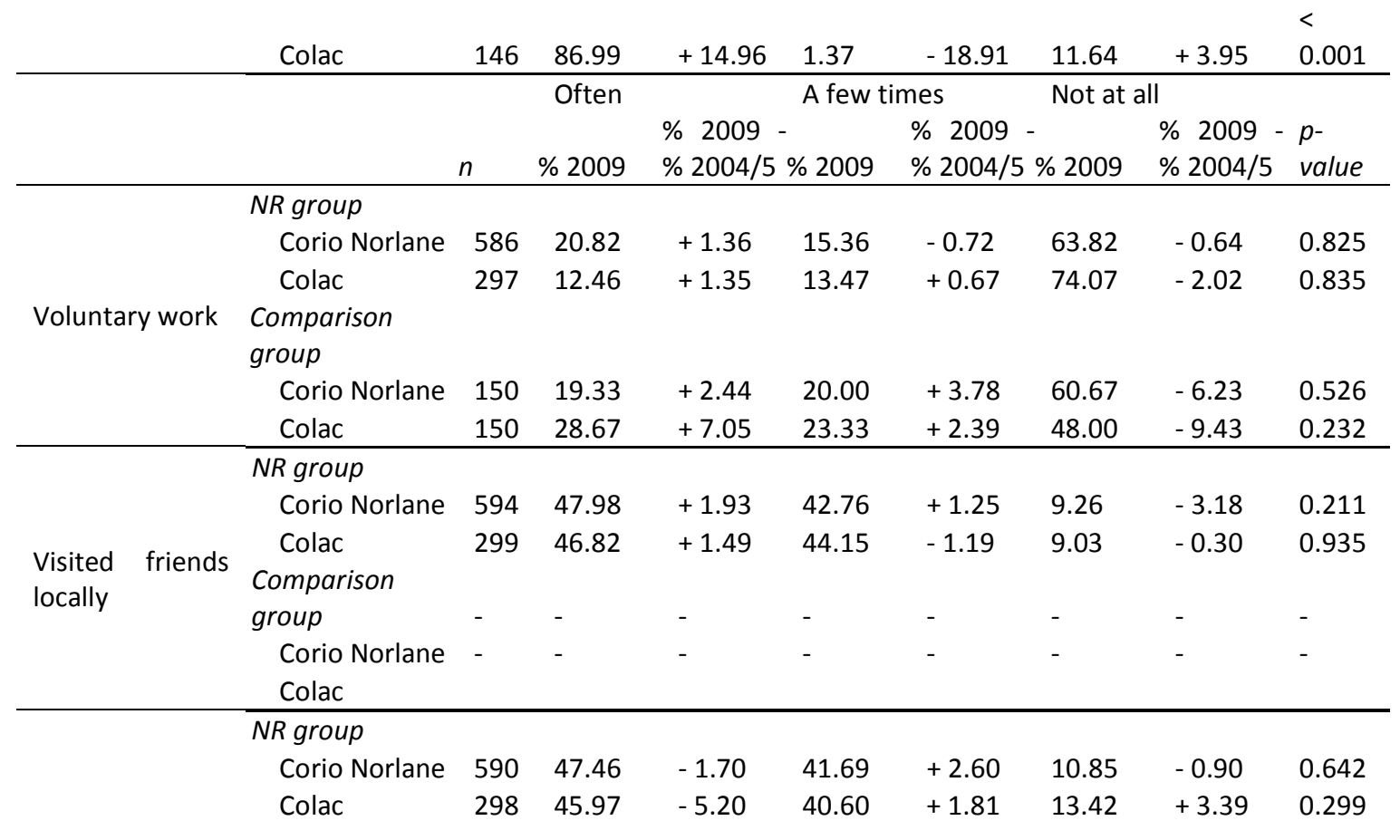

Spoken to your

neighbour

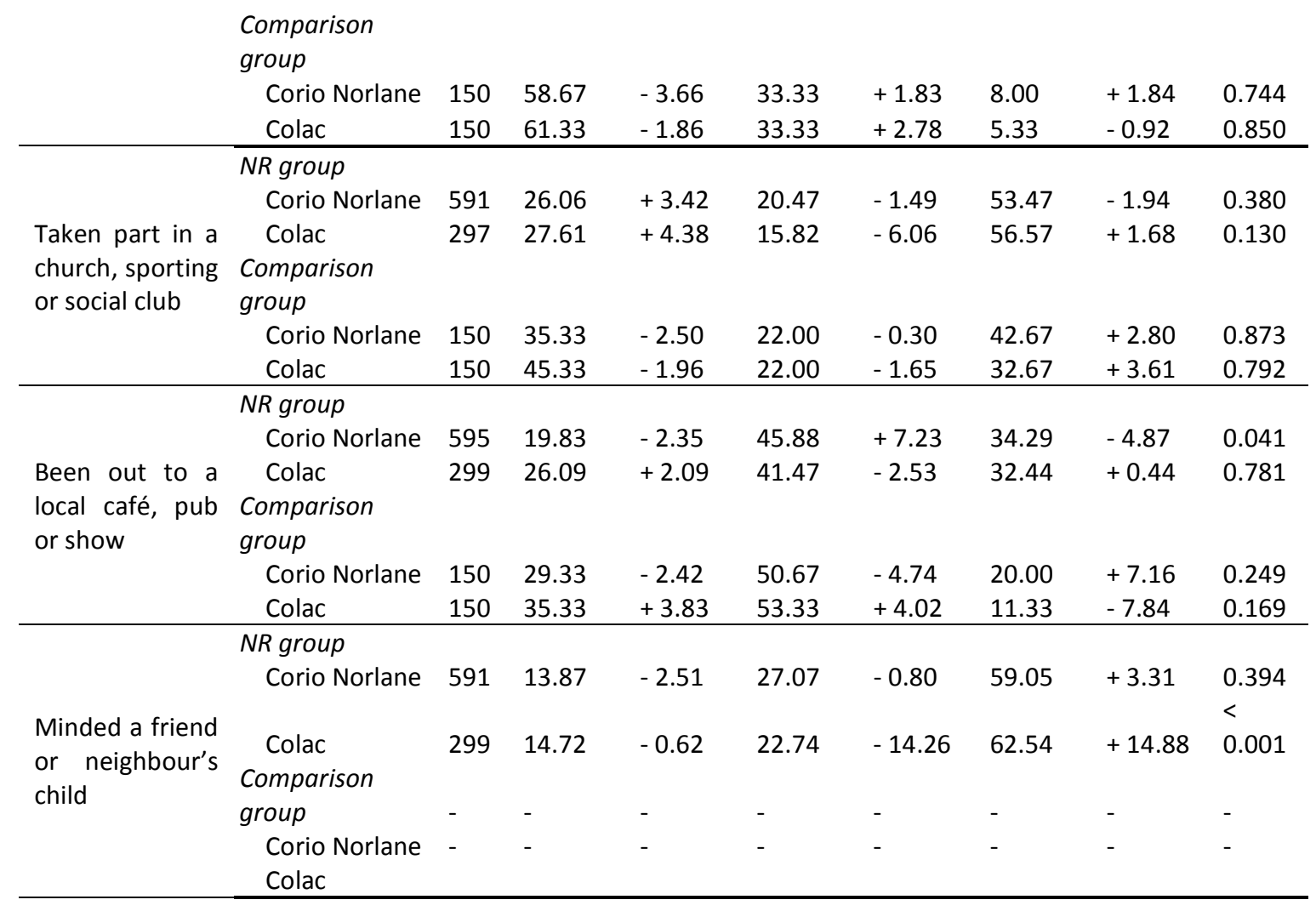


Neighbourhood renewal: an effective way to address social inclusion

\section{References}

Adams, R., Howard, N., Tucker, G., Appleton, S., Taylor, A., Chittleborough, C., et al. (2009). Effects of area deprivation on health risks and outcomes: a multilevel, cross-sectional, Australian population study. International Journal of Public Health, 54(3), 183-192. doi: 10.1007/s00038-009-7113-x

Allsop, J., \& Taket, A. (2003). Evaluating user involvement in primary healthcare. International Journal of Healthcare Technology and Management, 5(1), 34-44.

Australian Bureau of Statistics. (2008). Information paper: an introduction to socioeconomic indexes for areas (SEIFA) 2006 Australian Bureau of Statistics

Australian Government. (2009). A stronger fairer Australia. Canberra: Australian Government.

Australian Social Inclusion Board. (2010). Social inclusion in Australia: how Australia is faring. Canberra: Australian Government

Baum, S., \& Gleeson, B. (2010). Space and Place: Social Exclusion in Australia's Suburban Heartlands. Urban Policy and Research, 28(2), 135-159.

Bouckaert, G., Laegreid, P., \& Van de Walle, S. (2005). Trust, quality measurement models, and value chain monitoring. Public Performance \& Management Review, 28(4), 460-464.

Clark, D., \& Southern, R. (2006). Comparing institutional designs for neighbourhood renewal: neighbourhood management in Britain and the régies de quartier in France. Policy \& Politics, 34(1), 173-191.

Deans, K. A., Bezlyak, V., Ford, I., Batty, G. D., Burns, H., Cavanagh, J., et al. (2009). Differences in atherosclerosis according to area level socioeconomic deprivation: Cross sectional, population based study. British Medical Journal, 339(7730), b4170.

Feldman, P., Warr, D., Tacticos, T., \& Kelaher, M. (2009). People, places and policies - trying to account for health inequalities in impoverished neighbourhoods. Australian \& New Zealand Journal of Public Health, 33(1), 17-24.

Feveile, H., Olsen, O., \& Hogh, A. (2007). A randomized trial of mailed questionnaires versus telephone interviews: Response patterns in a survey. BMC Medical Research Methodology, 7(1), 27.

Forde-Roberts, V. (1999). Working for patients? An analysis of some effects of National Health Service reforms in High Wycombe. Unpublished PhD, London South Bank University, London.

Halachmi, A., \& Holzer, M. (2010). Citizen participation and performance measurement: operationalizing democracy through better accountability. Public Administration Quarterly, 34(3), 378-399.

Hemphill, S. A., Toumbourou, J. W., Smith, R., Kendall, G. E., Rowland, B., Freiberg, K., et al. (2010). Are rates of school suspension higher in socially disadvantaged neighbourhoods? An Australian study. Health Promotion Journal of Australia, 21(1), 12-18.

Major, J. M., Doubeni, C. A., Freedman, N. D., Yikyung, P., Min, L., Hollenbeck, A. R., et al. (2010). Neighborhood Socioeconomic Deprivation and Mortality: NIH-AARP Diet and Health Study. PLOS ONE, 5(11), 1-6. doi: 10.1371/journal.pone.0015538

Monks, R., \& Robertson, S. (2009). Evaluation of a neighbourhood health and wellbeing programme: Rob Monks, Steve Robertson and Gulab Singh outline the findings of an evaluation of the health and wellbeing aspect of 
Neighbourhood renewal: an effective way to address social inclusion

Neighbourhood Renewal Fund programmes. Primary Health Care, 19(3), 3438.

Neighbourhood Renewal. (2010a, December 3 2010). Action areas Retrieved May 31, 2011, from http://www.neighbourhoodrenewal.vic.gov.au/action-areas

Neighbourhood Renewal. (2010b, August 19 2010). Project areas Retrieved May 31, 2011, from http://www.neighbourhoodrenewal.vic.gov.au/projects

Popay, J., Escorel, S., Hernandez, M., Johnston, H., Mathieson, J., \& Rispel, L. (2008). Understanding and tackling social exclusion. Final report to the WHO commission on social determinants of health from the social exclusion knowledge network, February 2008.

Salvaris, M., \& Swinburne Institute for Social Research. (2008). Neighbourhood renewal community survey: Neighbourhood Renewal Victoria.

Scutella, R., \& Wilkins, R. (2010). Measuring Social Exclusion in Australia: Assessing Existing Data Sources. Australian Economic Review, 43(4), 449463. doi: 10.1111/j.1467-8462.2010.00611.x

Social Inclusion Unit. (2011). Overview of programs and initiatives Retrieved May 31, 2011, from http://www.socialinclusion.gov.au/Initiatives/Pages/default.aspx

Stafford, M., Nazroo, J., Popay, J. M., \& Whitehead, M. (2008). Tackling inequalities in health: evaluating the New Deal for Communities initiative. Journal of Epidemiology \& Community Health, 62(4), 298-304.

Stewart, M., Reutler, L., Makwarimba, E., Veenstra, G., Love, R., \& Raphael, D. (2008). Left out: Perspectives on social exclusion and inclusion across income groups. Health Sociology Review, 17(1), 78-94.

Taket, A., Crisp, B., Nevill, A., Lamaro, G., Graham, M., \& Barter-Godfrey, S. (Eds.). (2009). Theorising social exclusion: Routledge.

Tanton, R., Harding, A., Daly, A., McNamara, J., \& Yap, M. (2010). Australian children at risk of social exclusion: a spatial index for gauging relative disadvantage. Population Space \& Place, 16(2), 135-150.

Thomson, H., Atkinson, R., Petticrew, M., \& Kearns, A. (2006). Do urban regeneration programmes improve public health and reduce health inequalities? A synthesis of the evidence from UK policy and practice (19802004). Journal of Epidemiology and Community Health, 60(2), 108-115. doi: 10.1136/jech.2005.038885

Yang, K., \& Holzer, M. (2006). The performance-trust link: Implications for performance measurement. Public Administration Review, 66(1), 114-126.

\section{Biographical Notes:}

Margaret Shield is a Research Assistant in the Centre for Health through Action on Social Exclusion (CHASE) and a Sessional Academic in the School of Health and Social Development, Deakin University.

Dr Melissa Graham is a Senior Lecturer and member of the Centre for Health through Action on Social Exclusion (CHASE) in the School of Health and Social Development, Deakin University. Dr Graham has ten years experience working in the area of public health and health promotion with a particular interest in women's health and social connectedness. 
Professor Ann Taket holds a chair in Health and Social Exclusion within the School of Health and Social Development, and is Director of the Centre for Health through Action on Social Exclusion (CHASE). Professor Taket has over thirty years experience in public health related research, with particular interests in research directed at understanding the complex interactions between social exclusion and health, in the design and evaluation of interventions to reduce health inequalities, the use of action research, participatory methods, and experiential learning, and prevention and intervention in violence and abuse.

\section{Acknowledgement}

The authors would like to thank the Neighbourhood Renewal Branch within the Department of Human Services Victoria for funding both the survey and its analysis. 